\title{
Altering the Microstructure Morphology by Ultrasound Melt Processing during 6XXX Aluminium DC-Casting
}

\author{
G. Salloum-Abou-Jaoude ${ }^{1,2}$, D.G. Eskin ${ }^{1}$, G.S.B. Lebon ${ }^{1}$, C. Barbatti ${ }^{3}$, P. Jarry ${ }^{2}$, M. Jarrett ${ }^{3}$ \\ ${ }^{1}$ BCAST, Brunel University London, Uxbridge, Middlesex, UB8 3PH, UK \\ ${ }^{2}$ Constellium, Parc Economique Centr'alp, CS10027, Voreppe, 38341 cedex, France \\ ${ }^{3}$ Constellium UTC, Brunel University London, Uxbridge, Middlesex, UB8 3PH, UK
}

\begin{abstract}
In this work, we have introduced power ultrasound in the sump during hot-top DC casting of $152 \mathrm{~mm} \varnothing$ billets to influence the aluminium grain growth morphology. Grains in the central part of the billet are highly dendritic and elongated towards the sonotrode position in the sump. We suggest that ultrasound generates acoustic flow in the sump counteracting natural convection, thereby affecting the direction of grain growth; this is supported by numerical modelling. We found that macrosegregation can be decreased by tuning the position of the sonotrode in the sump and the ultrasonic power. Apart from the central part of the billet, the grain size was found to be significantly refined compared with the reference cast. This could be an effect of forced dendritic fragmentation by ultrasonic melt processing.
\end{abstract}

Keywords: DC casting, Ultrasonic processing, 6XXX series aluminium alloys, Microstructure, Dendritic morphology, Grain refinement, Acoustic cavitation, Numerical modelling

\section{Introduction}

Ultrasonic melt processing (USP) is a technology which can improve the quality of the as-cast metal, which includes increased soundness (through degassing) and a refined, uniform microstructure (through enhanced heterogeneous nucleation and fragmentation of crystals). In application to direct-chill (DC) casting of light alloys, this technology has been developed and successfully demonstrated on the pilot and industrial scales in the 1980s in the USSR [1, 2]. Later-on, grain refining with USP was superseded by the introduction of AITiB grain refiners which offered an efficient and easy solution. In recent years, however, the interest in USP for the purposes of grain refining (as well as melt degassing and manufacturing of composite materials) has been growing because that USP does not require chemical additions and does not produce harmful emissions.

There are two main mechanisms of structure refinement upon USP: enhanced heterogeneous nucleation (due to the improved wetting, activation, and deagglomeration of potential substrates) and fragmentation of primary crystals and dendrites. The former mechanism acts when USP is applied above the liquidus of an alloy; the latter occurs when USP is performed during solidification, i.e. below the liquidus. An important parameter of USP in DC casting is the location of ultrasonic sources (sonotrodes) in the sump of a billet. In such a case, both refining mechanisms maybe active with the significance of their contribution changing depending on the distance between the tip of a sonotrode and the liquidus isotherm in the sump. The closer the sonotrode is to the liquidus, the more pronounced the effect of fragmentation will be. 
Recently the role of acoustic streaming in the fragmentation of primary crystals has been revealed by insitu observations [3]. Prior to that, melt convection has been known to affect the growth direction of dendrites [4] and solute distribution both at the macroscopic [5] and the microscopic [6] scales. The last effect contributes to solute-driven fragmentation.

In this paper we present the results on the ultrasonic processing performed in the sump of an extrusion billet upon DC casting with the aim to understand the role of fragmentation and streaming on the grain structure. The experimental results are supported by computer simulations.

\section{Experiments}

An AA6XXX-series alloy was cast in Advanced Metal Casting Centre (AMCC) of the Brunel Centre for Advanced Solidification Technology (BCAST), Brunel University London. A hot top DC casting mold 152 $\mathrm{mm}$ in diameter was used to produce billets up to $2 \mathrm{~m}$ long. USP was performed using a water-cooled 5$\mathrm{kW}$ magnetostrictive transducer (Reltec) operating at $17.3 \mathrm{kHz}$ with a conical ceramic sonotrode with a working diameter of $24 \mathrm{~mm}$. Two power settings were used $2 \mathrm{~kW}$ and $3.5 \mathrm{~kW}$. The working end of the sonotrode was positioned in the hot top either at $h=10 \mathrm{~mm}$ (low) or $\mathrm{h}=100 \mathrm{~mm}$ (high) above the lower edge of the hot top (Fig. 1). At least $0.5 \mathrm{~m}$ of the billet was cast for each experimental setting to ensure the steady-state conditions. In all cases the alloys were grain refined with $0.1 \mathrm{wt} \%$ addition of an Al3TiB grain refining rod. Table 1 gives a summary of the experiments.

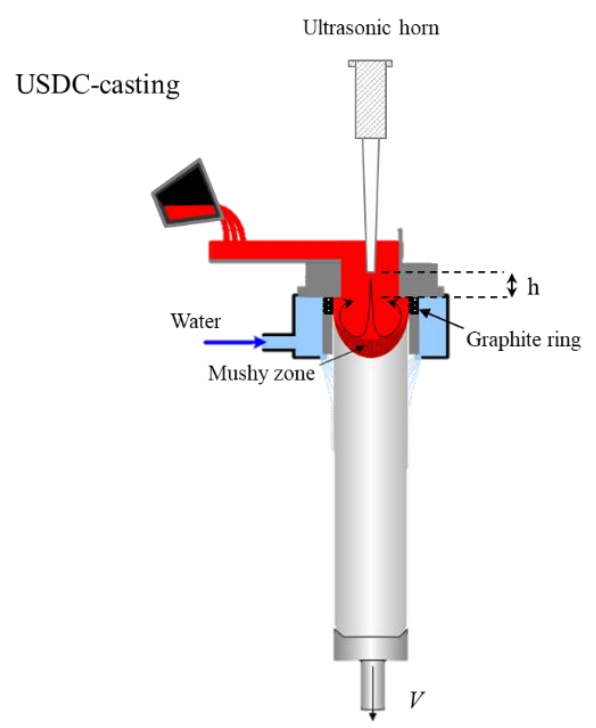

Figure 1: USDC casting setup with the ultrasound horn positioned at a high " $\mathrm{h}$ " from the bottom of the hot top

After casting, the billets were cut in the horizontal direction in the middle of the cast length, and the chemical composition was measured in two diametric directions normal to each other by optical emission spectroscopy (Foundry Master). The graph in Fig. 2 shows an example for two experiments. Samples were cut in the central, off-center and half-radius locations, polished and anodized in the longitudinal direction then examined under an optical microscope for grain structure. The grain size was measured by using the random linear intercept method and statistical analysis of the data was 
performed. Computer simulations were performed using our own modelling approach implemented in OpenFOAM 6. The details can be found elsewhere [7].

Table 1. Summary of experiments

\begin{tabular}{lllll}
\hline Billet & Exp. Name & Transducer power, kW & Position of sonotrode & Cast length, mm \\
\hline & E1 & - & - & 500 \\
1 & E2 & 2 & High & 700 \\
& E3 & 3.5 & High & 700 \\
\hline 2 & E4 & 2 & Low & 600 \\
& E5 & 3.5 & Low & 850 \\
\hline
\end{tabular}

\section{Results}

\section{Macrosegregation}

Macrosegregation was assessed as the overall deviation of the concentration of major alloying elements from the average, with $\sigma_{i}$ the deviation in \% from the average value for an element " $i$ ":

$$
\sigma_{T o t}=\sqrt{\frac{1}{N} \sum_{i=1}^{N} \sigma_{i}{ }^{2}}=\sqrt{\overline{\sigma^{2}}}
$$

$\sigma_{\text {Tot }}$, rel.\%

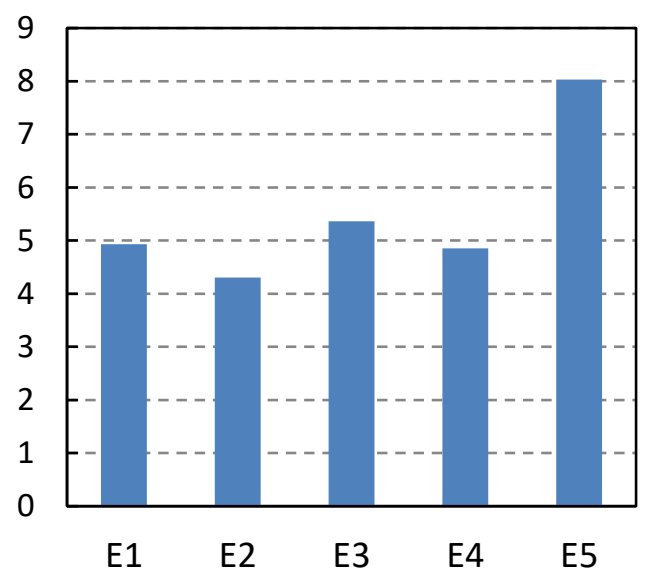

Relative macrosegregation wt\% Si

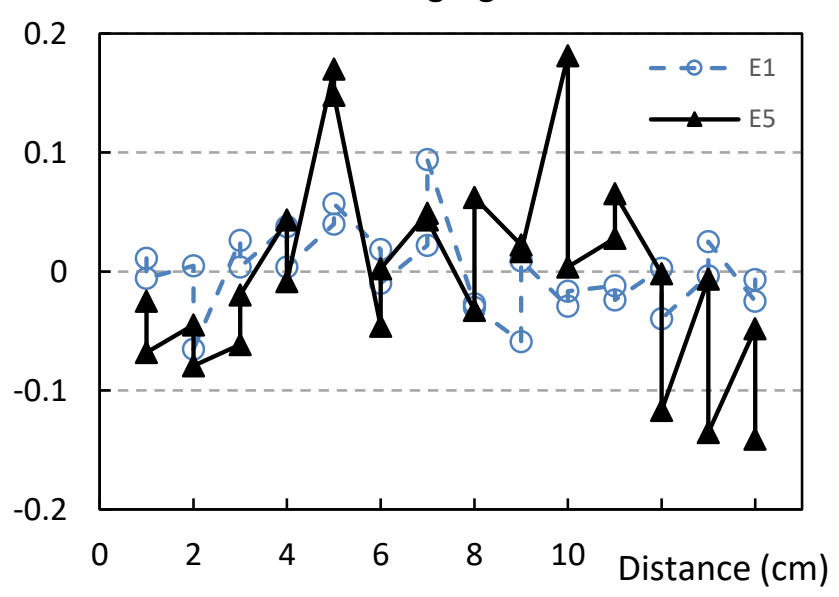

Figure 2: Macrosegregation analysis of the cast billets (see Table 1).

The results in Fig. 2 show that USP performed at a higher power and closer to the liquidus (case E5 lower position) resulted into an increased macrosegregation with significant positive segregation at 20 
$\mathrm{mm}$ off centre. This is an interesting result caused by acoustic streaming which generates a downward flow in the centre of the billet. In the other case, when the sonotrode was operated at a lower power and higher in the hot top, the relative macrosegregation was comparable with the reference cast E1.

\section{Grain structure}

The grain structure was examined in the central parts of the billets and at half-radius position. Fig. 3 shows the microstructure of the billets at half-radius positions demonstrating remarkable grain refinement in the cases E4 and E5. Fig. 4 illustrates an interesting grain morphology which has been observed in the off-center position ( $15 \mathrm{~mm}$ from the center of the billet): the billets that were cast with the lower position of the sonotrode developed dendritic grains inclined toward the centerline of the billet.

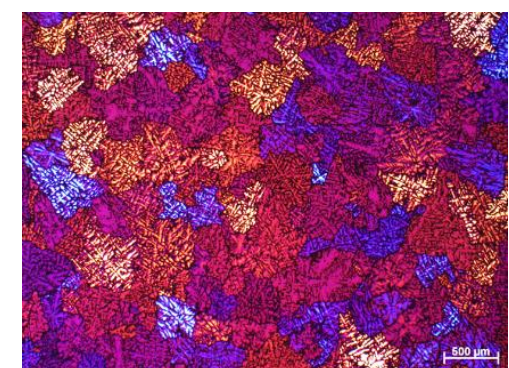

a

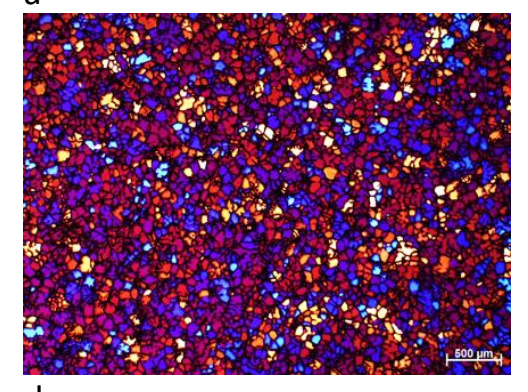

d

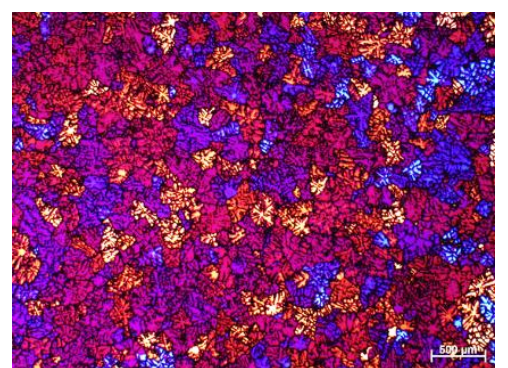

b

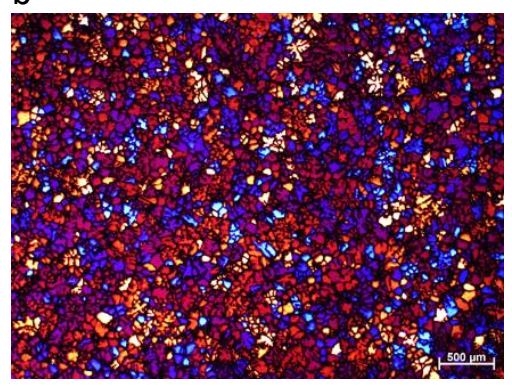

e

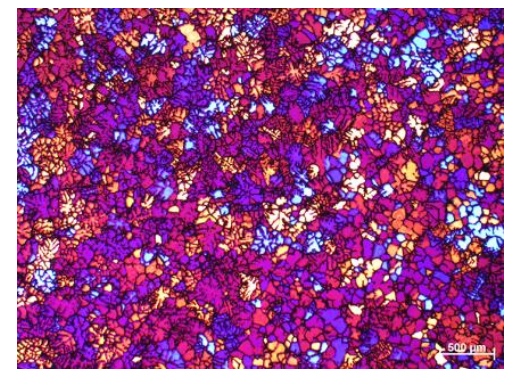

C

Figure 3: Grain structure at half-radius position of the experimental billet (see Table 1): a, E1 (no USP); b. E2 (USP, 2 kW, high); c, E3 (USP, 3.5 kW, high); d, E4 (USP, 2 kW, low); and e, E5 (USP, 3.5 kW, low) 

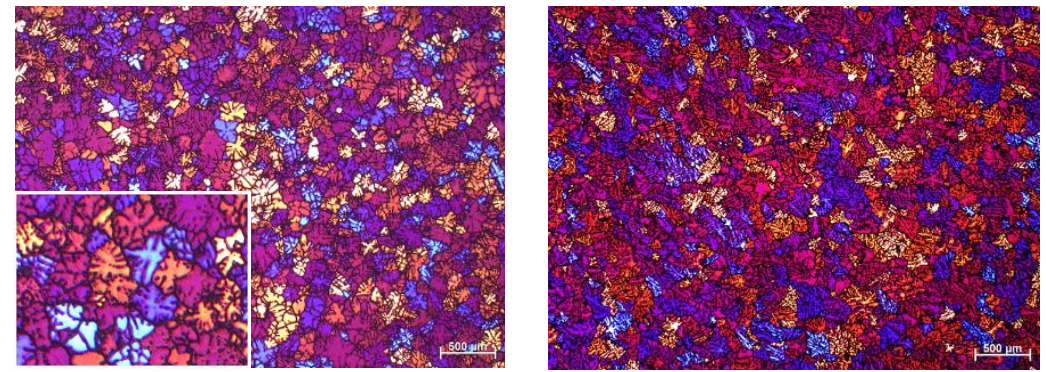

a

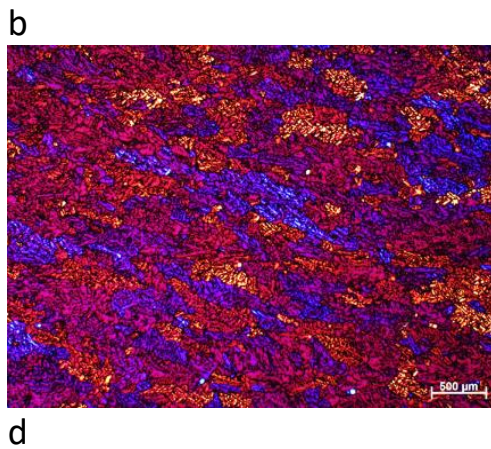

C

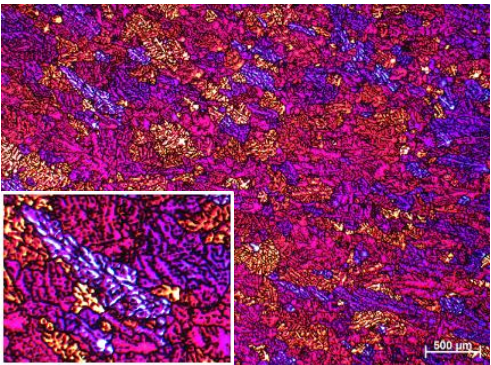

d

Figure 4: Grain structure at the $15 \mathrm{~mm}$ off center position of the experimental billet (see Table 1): a, E1 (no USP); b. E2 (USP, 2 kW, high); c, E4 (USP, 2 kW, low); and d, E5 (USP, 3.5 kW, low)

The measurement results for grain size and dendrite arm spacing (SDAS) are given in Fig. 5. These data show that the grains are progressively refined with the increase of the USP power and upon lowering the position of the sonotrode, except for the central portion of the billet where an opposite trend is observed. The dendrite arm spacing which is a measure of the local solidification time is consistently smaller upon USP.
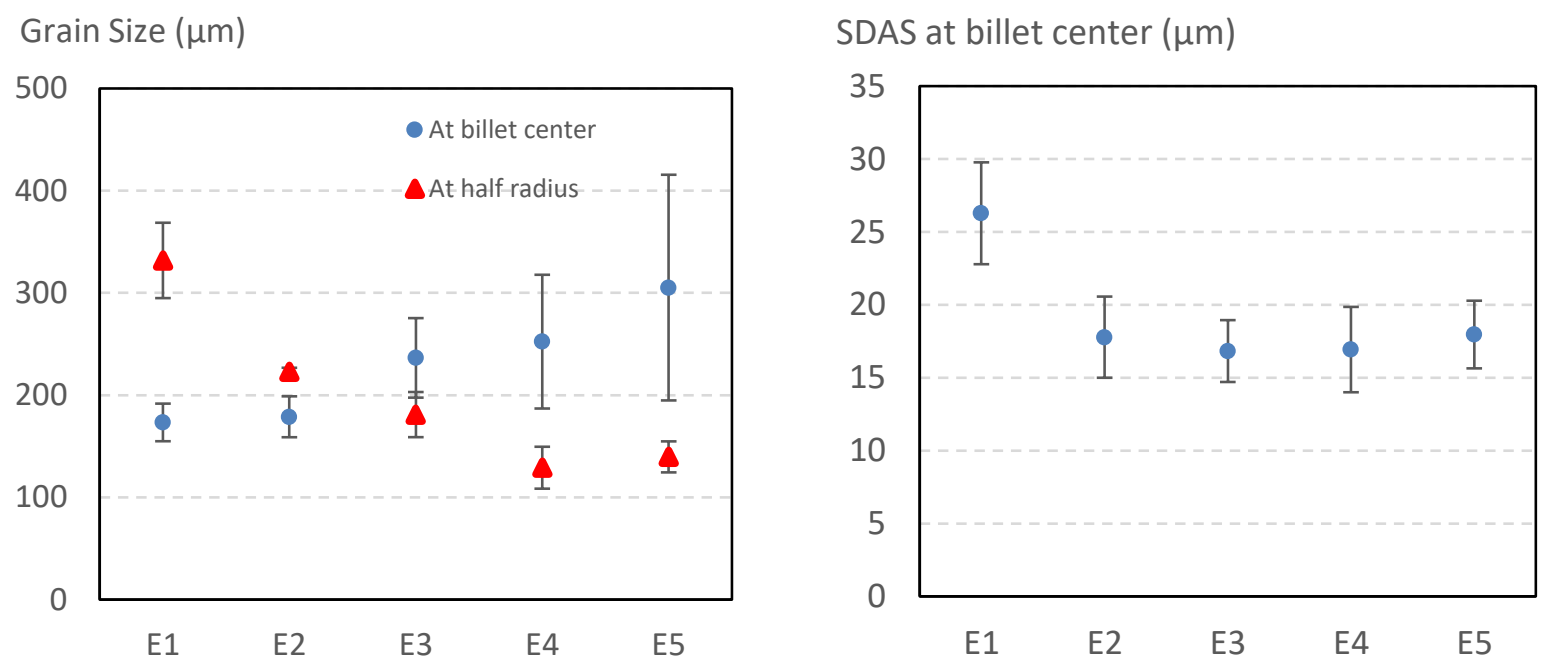

Figure 5: Grain size and dendrite arm spacing in the cast billets (see Table 1)

\section{Discussion}

Several interesting observations have been made in this series of USP experiments: (a) lowering of the sonotrode in the hot top results in a more pronounced grain refining in the bulk of the billet; (b) the USP closer to the liquidus results in the inclination of the dendritic grains toward the centerline of the billet 
and overall coarsening of grain structure in the central part of the billet; (d) the USP decreases the dendrite arm spacing of dendritic grains; and (c) increasing the USP power along with lowering the sonotrode position aggravates macrosegregation.

Some of these observations can be explained from the general knowledge of USP principles and mechanisms. When ultrasonic cavitation and streaming happen closer to the liquidus, solidification of the primary phase is directly affected, causing mechanical fragmentation of dendrite branches. Fragmentation can also be increased when a forced fluid flow changes the temperature and solute profiles in the mushy zone leading to dendrite ripening and fragmentation. This is already effective at the higher position of the sonotrode when the USP power is sufficiently high (E3, Fig. 3d): a duplex grain structure can be observed where the smaller grains are probably detached fragments. On lowering the sonotrode position, dendritic fragmentation becomes the main mechanism of structure formation with fine grain formed everywhere. One can notice that this is true except for the central portion of the billet. At this location, the grains become coarser and also inclined towards the central axis of the billet. The explanation of this interesting and (to our knowledge) not-reported-before phenomenon lies in the acoustic streaming caused by the working sonotrode. Fig. 6 shows computer simulated flow patterns for some typical cases assuming an amplitude of $50 \mu \mathrm{m}$ peak-to-peak.

USP produces strong downstream flow which is directed opposite to natural convection. The flow velocity increases with the power of USP. This ultrasound-induced flow has several consequences illustrated by the observations made in this study. Firstly, hot liquid brought from the top of the sump lowers the position of the liquidus, effectively decreasing the local solidification time in the central part of the billet via an increase in the temperature gradient thus causing the reduced dendrite arm spacing (see Fig. 5). Also, in this central region, there is no room for dendrite transport and maturation, which also contributes to dendrite arm spacing reduction.
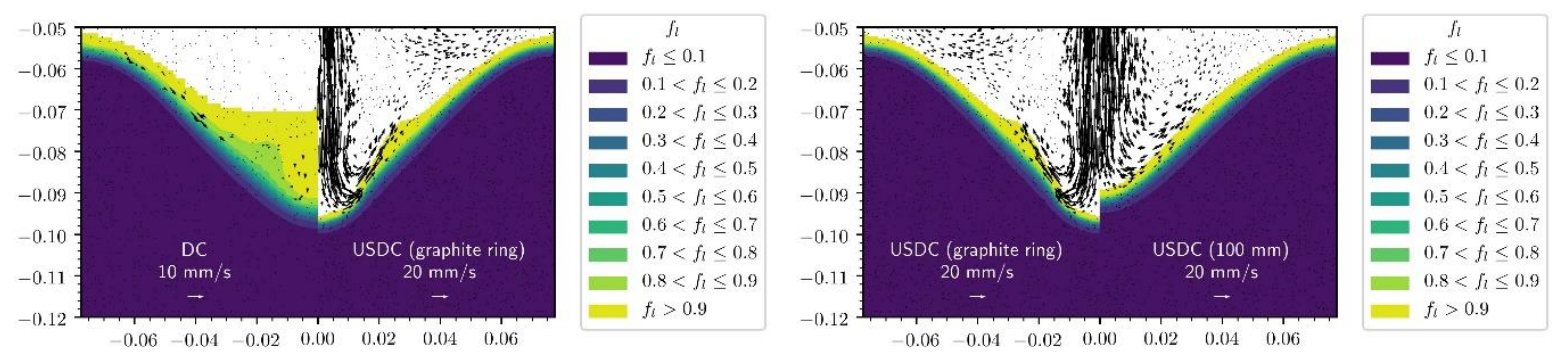

Figure 6: Numerically simulated flow patterns for the cases without USP (DC); high position of the sonotrode (USDC $100 \mathrm{~mm}$ ) and low position of the sonotrode (USDC graphite ring).

There are several accounts of the influence of flow on the dendrites growth direction. Okamoto et al. studying transparent cyclohexanol dendritic columnar growth had observed deflection of primary trunks towards the in-coming imposed flow together with the selection of the secondary arms that grew against the flow. [8]. Experimental studies of $\mathrm{NH} 4 \mathrm{Cl}$ equiaxed crystals settling in a liquid pool [9-11] have revealed that the downward primary arm of the grain facing the flow experienced greater growth rate than the opposite, downstream one, resulting in elongated grains. The secondary arm growth was also much more significant on the leading edges of the horizontal primary arms compared with their trailing edges. 3D phase field simulations [12] have shown that when an equiaxed grain is growing facing a fluid flow, the flow advects heat from the upstream to the downstream side of the grain. The temperature field becomes very asymmetrical around the equiaxed grain and the temperature gradient is at its 
highest at the dendrite tip in the upstream location. At this stage, the dendrite tip facing the largest temperature gradient grows at a faster velocity than its neighbors resulting in an elongated dendritic grain in the direction of the fluid flow. From the thermal point of view, it is also well known that, according to Hunt's classical Columnar to Equiaxed Transition model (CET) [13] a higher temperature gradient favors columnar grains over equiaxed grains. Among the many illustrations of this trend, let us mention in situ X-ray investigation of Al-3.5wt\%Ni Bridgman solidification experiments [14] which have showed that at the CET, equiaxed grains can be elongated in the direction of the temperature gradient if the cooling rate is not high enough for a given temperature gradient.

Our modeling shows dramatic increase in the temperature and solid fraction gradients in the case of USDC when acoustic streaming is introduced. The combination of our numerical simulation and the understanding we have from literature in terms of fluid flow influence on growth, CET model and phase field case studies teaches us that the coupling between fluid flow and thermal effects created by acoustic streaming results in faster, more directional growth of the grains. Hence the observation of elongated grains with significantly smaller SDAS in the case of USDC than in the reference cast (Fig. 5).

Besides the reduction of the solidification time and the associated reduction of dendrite arm spacing, such a modification of the flow pattern should also have consequences upon macrosegregation. Macrosegregation results from the relative movement between solid and liquid phases. Acoustic streaming may thus have two distinct effects: on the flow within the coherent mush, and on the movement of floating dendrites. At the center of the billet, the flow within the mush converges downwards due to natural convection, but this pattern may be reverted by acoustic streaming, depending on its intensity, which is governed by the ultrasonic power and the sonotrode position. Shear flow at the front is predicted to be enhanced on either side of the jet, which accounts for grain refinement at mid-radius.

From the simulation results, one can see that a very strong flow will generate non homogeneous temperature gradients across the radius of the billet. The grains will not be able to move in the center of the billet because of the increased temperature gradient, compared with the reference cast. However, the very strong flow may result in dendrite ripening, increasing fragmentation and the displacement of the loose grains and fragments from the central part of the billet, spreading those to the other parts of the sump.

From the results of our simulation in the case of USDC, we can see that the temperature gradient is at its smallest value at $20 \mathrm{~mm}$ off center. Hunt's CET criterion predicts that it is the location where equiaxed growth is most promoted. Furthermore, transportation of free grains and fragments away from the billet center by the strong flow (case E5) brings a further contribution to the seeding of the liquid, accounting for the intense grain refinement around half-radius, see Fig. 3 and 5. The associated flow within the mush up to this region could explain the peak in macrosegregation observed at $20 \mathrm{~mm}$ off center in E5 (Fig. 2) due to eutectic rich liquid migration. 


\section{Conclusions}

1. Ultrasonic melt processing performed in the sump during hot top DC casting of an AA6XXX-series alloy shows a strong effect of the power and position of the sonotrode on the formation of grain structure and macrosegregation.

2. In addition to the well-known effects of dendrite fragmentation by cavitation bubbles, acoustic streaming induced by USP needs to be taken into account when interpreting the observed phenomena.

3. A special grain morphology with grain elongated towards the centerline of the billet can be explained by the direction and power of acoustic streaming in this part of the billet.

4. The dendrite fragmentation becomes more pronounced when a high-power ultrasound is applied close to the solidification front in the billet sump. At the same time, in the central region where acoustic streaming hits the front, a trend toward equiaxed to columnar transition is observed.

5. For an USP power of $2 \mathrm{~kW}$ and a position of the sonotrode bottom within the hot top $100 \mathrm{~mm}$ above the mold, grain structure uniformity was improved across the billet section and the SDAS was reduced in the center of the billet with no increase in macrosegregation in comparison with the reference cast. This suggests that acoustic streaming may be used to tune and tailor as cast structures in DC Casting.

\section{Acknowledgments}

Financial support from EPSRC (UK) under projects LiME Hub (EP/N007638/1) and UltraMelt2 (EP/R011001/1, EP/R011044/1 and EP/R011095/1) is gratefully acknowledged.

\section{References}

1. G.I. Eskin, Ultrasonic processing of aluminum alloy melts, Moscow, Metallurgiya, 1988

2. G.I. Eskin, D.G. Eskin, Ultrasonic treatment of light alloy melts, Boca Raton, CRC Press, 2015

3. F. Wang, D. Eskin, J. Mi, C. Wang, B. Koe, A. King, C. Reinhard, T. Connolley. Acta Mater., 2017, vol. 14, pp. $142-153$

4. K. Murakami, T. Fujiyama, A. Koike, T. Okamoto. Acta Metall., 1983, vol. 31, pp. 1425-1432

5. D.G. Eskin, A. Jafari, L. Katgerman. Mater. Sci. Technol., 2011, vol. 27, pp. 890-896

6. D. Ruvalcaba, R.H. Mathiesen, D.G. Eskin, L. Arnberg, L. Katgerman. Acta Mater., 2007, vol. 5, pp. $4287-$ 4292

7. G.S.B. Lebon, G. Salloum-Abou-Jaoude, D. Eskin, I. Tzanakis, K. Pericleous. Computational Material Science, 2018 (submitted)

8. T. Okamoto and K. Kishitake, Journal of Crystal Growth, 1975, vol. 29, pp. 131-136

9. A. Ramani, C. Beckermann, Scripta Mater., 1997, vol. 36, no. 6, pp. 633-638

10. B. Appolaire, V. Albert, H. Combeau and G. Lesoult, Acta mater., 1998, vol. 46, no. 16, pp. 5851-5862

11. J.A. Dantzig and M. Rappaz, Solidification, EPFL Press, distributed by CRC Press, 2009

12. Y. Lu, C. Beckermann, A. Karma, ASME International Mechanical Engineering Congress \& Exposition November 17-22, 2002, New Orleans, Louisiana, IMECE2002-32838

13. W. Kurz, D.J. Fisher, Fundamentals of solidification, Enfield Publishing \& Distribution Company, 1992

14. G. Reinhart, H. Nguyen-Thi, N. Mangelinck-Noël, B. Billia and T. Schenk, J. Baruchel, IOP Conf. Series: Materials Science and Engineering 2011, 27, 012011 